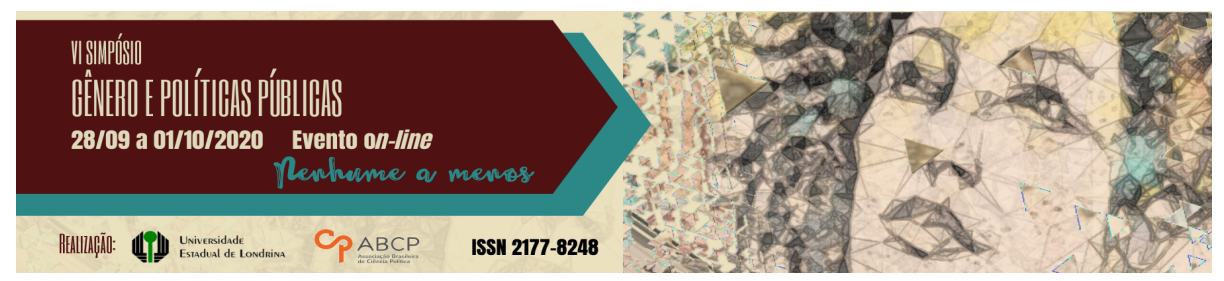

\title{
Feminicídios em debate: notas sobre as lutas dos movimentos feministas locais no combate à violência contra mulher em Cuiabá (MT)
}

\author{
Cleide Aparecida Leme de Souza ${ }^{\text {; }}$ Silvana Maria Bitencourt ${ }^{2}$
}

\begin{abstract}
Resumo
Considerando que os casos de feminicídios devem ser tratados como crimes bárbaros, pois confirmam a ordem patriarcal, esta que ainda ocorre na sociedade brasileira atingindo muitas mulheres, principalmente as mulheres mais pobres e negras. Neste sentido este relato de experiência procura expor alguns casos de feminicídios em Cuiabá a fim de questionar como têm sido tratados os casos de feminicídios pela sociedade cuiabana. A articulação dos grupos feministas de Cuiabá busca dar visibilidade através das redes sociais, sensibilizando outras mulheres para se mobilizarem em atos e manifestações, em busca de combater os Feminicídios, baseando-se na Lei Maria da Penha $n$ 11.340/2006, e na Lei do Feminicídio n 13.104/2015. Atualmente o Estado de Mato Grosso é o terceiro Estado no ranking nacional de mulheres vítimas de feminicídios no Brasil.
\end{abstract}

Palavras-chaves: violência contra a mulher; feminicídio; violência doméstica; movimentos feministas.

\footnotetext{
1Graduanda em Licenciatura em Ciências Sociais da Universidade Federal de Mato Grosso (UFMT), E-mail:cleideaparecidaleme@gmail.com

2 Professora Associada I do Departamento de Sociologia e Ciência Política da Universidade Federal de Mato Grosso e do Programa de Pós- Graduação em Sociologia; Doutora em Sociologia Política pela UFSC; E-mails: silvanasocipufmt@gmail.com.
}

GT 06 - Gênero, cuidado e políticas de saúde 


\section{Debating feminicides: notes on the struggles of local feminist movements in the fight against violence against women in Cuiabá} (MT)

\section{Resume}

Considering that cases of femicide should be treated as barbaric crimes, as they confirm the patriarchal order, which still occurs in Brazilian society, affecting many women, especially the poorest and black women. In this sense, this experience report seeks to expose some cases of femicide in Cuiabá in order to question how the cases of femicide have been treated by the cuiabana society. The articulation of feminist groups in Cuiabá seeks to give visibility through social networks, sensitizing other women to mobilize themselves in acts and demonstrations, in search of combating Feminicides, based on the Maria da Penha Law No. 11.340 / 2006, and on the Law of Feminicide No. 13,104 / 2015. Currently, the State of Mato Grosso is the third state in the national ranking of women victims of femicides in Brazil.

Keywords: Violence against women, feminicide, domestic violence, feminist movements.

Feminicídios em debate: notas sobre as lutas dos movimentos feministas locais no combate à violência contra mulher em CuiabáMT

A violência contra a mulher afeta diariamente milhares de mulheres independente da faixa etária, classe social, raça/ etnia, grau de instrução etc. No Brasil nos últimos anos houve avanços significativos em termos de implementação de políticas públicas de enfrentamento a violência de gênero. Contudo, a gravidade das situações de violência vivenciada pelas mulheres ainda requer muita atenção a ser realizada no sentido de garantir o direito das mulheres vítimas de violência.

Assim, este relato trata do trabalho de conclusão de curso em Licenciatura em Ciências Sociais da Universidade Federal de Mato Grosso, que se encontra em andamento e tem como objetivo central analisar os principais motivos em que as mulheres são vítimas de violência de gênero na cidade de Cuiabá, bem como contextualizar a temática e os avanços das lutas das mulheres frente ao enfrentamento, 
se baseando na Lei $\mathrm{n}^{\mathrm{o}} 11.340 \backslash 2006$ Maria da Penha e a Lei Feminicídio $n^{\mathrm{o}} 13.104 \backslash 2015$.

A pesquisa se caracteriza como uma pesquisa bibliográfica e exploratória, buscando a partir das referências documentadas qualificar as informações obtidas. A revisão bibliográfica é uma análise crítica, minucioso e ampla das publicações correntes em uma determinada área de conhecimento, procurando explicar e discutir um tema com base em referências teóricas publicadas em livros, revistas científicas, periódicos entre outros. Para obtenção de dados sobre as notícias que circulam nos meios de comunicação serão realizadas pesquisas em mídias sociais (jornais) e em outros meios de acesso às informações sobre violência contra mulheres, que veiculem notícias de grande repercussão referentes à cidade de Cuiabá.

A pesquisa pauta-se na abordagem qualitativa e quantitativa do período de 2018 a 2020, tendo como foco principal os casos de assassinatos $^{3}$ de mulheres em 2012. Tendo em vista a violência praticada contra as mulheres causa inúmeras consequências físicas e psicológicas para a saúde delas, gerando prejuízos tanto de ordem física, cognitiva quanto emocional ou afetivo.

Saffioti (2015, p. 83) "analisa o fenômeno da violência contra a mulher como inerente ao padrão das organizações desiguais de gênero que, por sua vez são tão estruturais quanto a divisão, ou seja, o gênero, a classe e a raça \etnia não igualmente estruturais das relações sociais."

Conforme Scott (1995, p. 86) “o gênero é um elemento constitutivo de relações sociais fundadas sobre as diferenças percebidas entre os sexos, é um modo primordial de dar significado as relações de poder".

Compreende se a dinâmica da desigualdade de gênero relacionada as situações econômicas ao capitalismo patriarcal vão de

${ }^{3}$ Considerando que não se abordava o termo feminicídio, e sim, os homicídios contra as mulheres, relacionados casos passionais. 
encontro com a vulnerabilidade das mulheres vítimas de violência. Segundo Teles; Melo "é uso da força física, psicológica ou intelectual para obrigar outra pessoa a fazer algo que não está com vontade; é constranger a outra pessoa de se manifestar seu desejo e sua vontade, sob ameaças ou até ser morta" (TELES; MELO, 2012, p. 13).

Bourdieu, em seu livro Dominação Masculina (2012, p. 47) retrata a violência como simbólica, pois, tenta minimizar essa violência física, na sua sutileza, desapercebida e até mesmo sendo naturalizada. Onde o termo "Feminicídio", foi utilizado pela primeira vez pela socióloga e feminista Diane Russel, conceitua-se baseando em assassinatos de mulheres por homens motivados pelo ódio, desprezo e o sentimento de propriedade. Russel apoiou-se na perspectiva da desigualdade de poder entre homens e mulheres, "e como de forma seletiva a imprensa sobre os crimes e na qual o sistema de justiça e segurança pública lidam com os casos de feminicídio" (RUSSEL, 1992 apud MARIANO, 2017).

No estado de Mato Grosso, em 2018, uma mulher era vítima de feminicídio a cada seis dias, sendo que, por dia, foram 55 mulheres ameaçadas e 27 sofreram lesões corporais. A cada um dia e meio, houve estupro. Os dados disponibilizados foram seguidos de levantamento através da Coordenadoria de Estatística e Análise Criminal (CEAC) Secretaria de Estado de Segurança Pública (SESP $\backslash$ MT). Segundo esse levantamento, $50 \%$ dos assassinatos foram motivados por crime passional, enquanto, a Defensora Pública do Estado de Mato Grosso, Rosana Leite Antunes de Barros, afirma que os casos de assassinatos de mulheres chegaram a $70 \%$, ou seja, foram 45 casos de feminicídios.

Em janeiro de 2020, Cuiabá não registrou nenhum caso, conforme a Delegacia de Homicídios e Proteção à Pessoa (DHPP). Já em 2018, foram 17 mulheres mortas, e 11 delas foram tipificadas com menosprezo ou discriminação à condição de ser mulher ou como violência doméstica. 
Essa realidade remete às relações patriarcais de gênero. No atual cenário de uma crise de saúde pública devido ao novo coronavírus, Mato Grosso está não só vivenciando uma pandemia, mas também um aumento de feminicídios no estado. Somente nos seis primeiros meses de 2020 , foram $68 \%$ a mais em relação ao mesmo período de 2019 . Neste ano, 32 mulheres foram vítimas de feminicídio, enquanto, em 2019, foram 19.

Os dados foram colhidos através da Observatório de Violência da Secretaria de Estado de Segurança Pública (SESP-MT), sendo que são dados preliminares, portanto, dependerão das investigações decorrentes dos casos.

As tragédias estão ganhando visibilidade provocada pela violência de gênero e cada vez mais surgem história de feminicídios em Cuiabá e no interior de Mato Grosso, o que nos faz um alerta para as graves consequências da cultura do patriarcado persistente no país.

O feminicídio ocorre quando seu agente considera que nada há mais como controlar a mulher em seu todo, tanto o corpo como os seus desejos e pensamentos. (Teles, 2012, p.49)

Mato Grosso é o terceiro estado que mais mata mulheres no Brasil, calculadas por estado a partir dos registros a partir da criação da Lei do ano de 2006, 2014 e 2015. Somente em 2018, Cuiabá teve aumento de $37 \%$ nos casos de feminicídios, embora a evolução do ciclo de violência ocorra dentro de casa, com o risco de morte iminente. Mesmo assim o estado deve ter o papel primordial no combate ao fim da violência contra a mulher criando uma rede de apoio para as mulheres se fortalecerem com segurança suficiente para que possa romper com os relacionamentos abusivos.

A violência de gênero ganhou visibilidade na mídia, porém, é banalizada, considerada algo corriqueiro e sem grandes consequências, mantendo a impunidade. (Teles, 2012, p.47) 
O primeiro caso de feminicídio no Brasil, foi a da socialite Ângela Diniz, em 1976. Pelo então companheiro, Raul “Doca” Fernando do Amaral Street, no balneário de Búzios, no Rio de Janeiro. Sendo condenado a dois anos de cadeia, cumprindo em liberdade, tendo como tese de defesa, por ter matado em defesa da honra e "matado por amor". Argumento esse, que os movimentos de mulheres se organizaram a criar o slogan "quem ama não mata". (Memória Globo, 2004)

A vítima é transformada em culpada e merecedora de sua morte e o culpado como vítima, naquela época imperava o machismo, e as mulheres eram oprimidas, submissas aos seus companheiros, e legitimada pala legislação.

Dentre vários casos de feminicídios em todo país, se destaca um ocorrido na capital do Estado de Mato Grosso, Cuiabá. Cuiabá foi palco de crimes bárbaros contra as mulheres. $\mathrm{O}$ caso de maior proporção e consternação, ocorreu em 03 de fevereiro de 2012, a vítima Katsué Stefane Santos Vieira de 23 anos, foi morta a facada e carbonizada dentro de um forno a lenha de uma pizzaria próximo avenida General Mello, no bairro Barbado. O réu confesso, Weber Melquis Venandes de Oliveira, foi condenado a 17 anos e 6 meses de prisão por homicídio qualificado e ocultação, e julgado pelo tribunal do júri.

Tendo em vista em que a Lei do Feminicídio não estava vigente naquela época, um crime bárbaro acometido por ódio e desprezo por ser mulher, pois, segundo ele, quando a conheceu (vitima) na boate sentiu à vontade imensa de matá-la, por isso a chamou para usar drogas na pizzaria do seu pai. Em 2017, o juiz Geraldo Fidelis, da $2^{\circ}$ Vara Criminal da capital, autorizou a soltura do réu, este que passou a usar a tornozeleira eletrônica para o cumprimento da pena em regime semiaberto.

Outro caso, de extrema repercussão no mesmo ano de 2012, precisamente 28 de maio, foi de Juliene Assunção Goncalves, a jovem foi encontrada nua e pendurada pelo pescoço, com a própria calça, na arquibancada do campo de futebol do Botafogo, no Bairro CPA III, em 
simulação a um suposto suicídio. O suspeito, em seu depoimento, admitiu dar carona, porém, alegou tê-la deixado em sua casa, após tentar sem sucesso a manter relações sexuais com ela. Com fortes provas contra ele, segundo a polícia, o aparelho de celular da vítima foi encontrado em seu carro, e o pedaço de fio elétrico semelhante ao usado no crime dentro do carro do suspeito, e mesmo assim, negou e o crime até hoje não foi solucionado.

\section{$\mathrm{O}$ ato \#maiojuliene}

Realizado através do coletivo "Mulheres do Hip Hop", o ato tinha como objetivo central cobrar da justiça solução no caso do assassinato da Juliene, que ocorreu em 2012. O ato aconteceu entre os anos de 2016 a 2018, ocorrendo no mês de maio, o mês da sua morte. O caso da Juliene ganha notoriedade através da articulação de mulheres de Cuiabá, em ir para as ruas, em protestar em busca de justiça, embora ainda o assassino esteja solto. $\mathrm{O}$ caso da Juliene tem sido um caso emblemático para outras mortes de mulheres não ficarem impunes, ou seja, no esquecimento da sociedade e principalmente, da justiça de Mato Grosso.

Ângela Diniz, uma socialite a frente do seu tempo da década de 70 , foi julgada de maneira cruel por ser mulher. O mesmo aconteceu com Juliene, julgada estritamente cruel, sendo uma mulher negra e da periferia e Katsué, por ser garota de programa.

Com este relato da pesquisa não pretendemos esgotar o assunto, por isso pretende-se que ela possa ser aporte para outras pesquisas no sentido de mostrar mais partes do todo, que compõem os intrincados casos de feminicídio.

\section{Referências}

BOURDIEU, P. A Dominação Masculina. Rio de Janeiro: Bertrand Brasil, 2012. 
CASTRO, L.W. S. O crime passional de Doca Street. Canal de ciências criminais. Disponível em: www.canalcienciascriminais.jusbrasil. Com.br. Acesso em: 23 fev. 2020

CÔRTES, G. R. A Informação no enfrentamento a Violência Contra Mulheres: Centro de Referência da Mulher "Ednalva Bezerra": relato de experiência. Biblionline, João Pessoa, v. 8, n. esp., p 134-15, 2012.

GAZETA DIGITAL. Feminicídio aumenta 37,5\% em Cuiabá e Várzea Grande. Disponível em:

https://www.gazetadigital.com.br/editorias/cidades/feminicidioaumenta-375-em-cuiabae-varzea-grande/563934. Acesso em: 16 nov. 2019.

G1. MT registra 21 casos de feminicídio no $1^{\circ}$ semestre de 2019 , diz governo. Disponível em: https://g1.globo.com/mt/matogrosso/noticia/2019/07/25/mt-registra-21-casos-de-feminicidiono1o-semestre-de-2019-diz-governo.ghtml. Acesso em: 16 nov. 2019.

IPEA, 2019. Disponível em

https://www.ipea.gov.br/portal/images/stories/PDFs/relatorio_i nstitucional/190605_atlas_da_violencia_2019.pdf Acesso em: 04 nov. 2019

JORNAL OESTE. Mato Grosso é o $2^{\circ}$ estado que mais mata mulheres no Brasil. Disponível em:

http:/ / www.jornaloeste.com.br/noticias/exibir.asp?id=49378\&notic ia=mato_grosso_e_o_2_estado_que_mais_mata_mulheres_no_brasil. Acesso em: 16 nov. 2019.

MARIANO, I.S.F. Feminicídio na imprensa: uma análise do jornal Folha de São Paulo. Curitiba/PR: Intercom- Sociedade Brasileira de Estudos Interdisciplinares da Comunicação $40^{\circ}$ Congresso Brasileiro de Ciências da Comunicação. Disponível em https:/ / portalintercom.org.br/anais/nacional2017/resumos/R120268-1.pdf Acesso em: 26 de ago. 2020

SAFFIOTI, H. I. B. Gênero Patriarcado Violência. São Paulo: Perseu Abramo. 2015.

SCOTT, J. Gênero: Uma categoria útil de análise histórica. Educação e Realidade. jul./dez. 1995. 